\title{
Water-Based Nanofluids for Natural Convection Cooling of a Pair of Symmetrical Heated Blocks Placed Inside a Rectangular Enclosure of Aspect Ratio Two
}

\author{
Afifa Riahi $^{a}$, Nader Ben-Cheikh ${ }^{a}$, Antonio Campo ${ }^{b} *$ \\ a Physics Department, Faculty of Sciences of Tunis, University of Tunis El-Manar, 2092 El-Manar II, Tunis, Tunisia \\ ${ }^{b}$ Mechanical Engineering Department, The University of Vermont, Burlington, VT 05405, USA
}

\begin{abstract}
Fluid flow structures and heat transfer rates in a rectangular enclosure of aspect ratio of two containing two heated cylindrical blocks and filled with various water-based nanofluids is investigated. The free space between the cylindrical blocks and the enclosure walls is filled with four nanofluids: $\mathrm{Cu}$-water, Ag-water, $\mathrm{Al}_{2} \mathrm{O}_{3}$-water and TiO controlling parameters to be considered are: the Rayleigh number $10^{3} \leq R a \leq 10^{6}$, the solid volume fraction of the nanoparticles $0 \leq \varphi \leq 0.06$, the inclination angle $0 \leq \gamma \leq 180^{\circ}$. A numerical methodology based on the finite volume method, united to a full multigrid acceleration is utilized for solving the coupled system of conservation equations under the Boussinesq platform. The numerical results are presented in tabular and graphical forms to elucidate the role played by the parameters on the complex nanofluid flows and the heat transfer characteristics. In general, it is found that there is heat transfer enhancement with water-based nanofluids. It is more pronounced at combinations of high volume fractions and low Rayleigh numbers. The collection of results suggests that the best heat transfer enhancement can be obtained by using $\mathrm{Cu}$-water nanofluids at moderate solid volume fractions around $\varphi=0.04$. Additionally, the inclination angle can be used as a control parameter for rectangular enclosures housing two equal heated blocks which are cooled with waterbased nanofluids.
\end{abstract}

Keywords: Water-based nanofluids, natural convection, two heated blocks, rectangular enclosure, aspect ratio of two, heat transfer enhancement

\section{Introduction}

Fluid flow and natural convection heat transfer inside enclosures is important for many apparatuses, such as nuclear reactors, heat exchangers, solar collectors, electronic cooling, etc. (Bejan [1]). The size, position and orientation of heat exchange devices can affect the performance of heat transfer. In addition to these parameters, changing properties of fluid affect the performance of heat transfer mechanism. In recent years, nanofluids, which are a mixture of nanometer-sized particles suspended in a base fluid, are used to increase the rate of heat transfer in many thermal applications and many practical engineering applications [2-4]. In this regard, thermophysical properties of nanofluids have been studied extensively by many researchers [5-9].

A literature review of natural convection in enclosures filled with nanofluids is exposed next. Khanafer et al. [10] investigated the buoyancy-driven fluid flow and heat transfer in a twodimensional rectangular enclosure with cold right wall, hot left wall, insulated horizontal walls and filled with $\mathrm{Cu}$-water nanofluid. These authors reported an augmentation in the rate of heat transfer with increments in percentage of the suspended nanoparticles for the considered range of Grashof number. Jou and Tzeng [11] showed similar results that emanated from a

${ }^{*}$ Corresponding author.

E-mail: campanto@yahoo.com

(c) 2018 International Association for Sharing Knowledge and Sustainability

DOI: 10.5383/ijtee.16.01.001 
numerical study of natural convection in differentially heated rectangular cavities filled with $\mathrm{Cu}$-water nanofluid. Those effects due to uncertainties in the effective dynamic viscosity and effective thermal conductivity of $\mathrm{Al}_{2} \mathrm{O}_{3}$-water nanofluid on natural convection heat transfer in a differentially heated square enclosure were investigated by $\mathrm{Ho}$ et al. [12]. The authors found that that heat transfer across the enclosure can be enhanced or mitigated with respect to the base fluid via the used dynamic viscosity formula. In another study, Ho et al. [13] experimentally investigated the natural convection of a water-based alumina nanofluid inside a differentially heated square cavity. The experimental results for the average heat transfer rate appear to be consistent with the assessment based on the changes in the thermophysical properties of the nanofluid formulated. Abu Nada and Oztop [14] investigated the natural convection of $\mathrm{Cu}-$ water nanofluid in an inclined square cavity using the finite volume method. In the publication, they showed that the inclination angle can be used as a control parameter for the fluid flow and heat transfer inside the cavity. Furthermore, their results indicated that effects of the inclination angle on the percentage of heat transfer enhancement became insignificant at low Rayleigh number.

Ogut [15] studied the natural convection in an inclined square cavity filled with different water-based nanofluids. He observed that the average heat transfer rate increased significantly as the nanoparticles volume fraction and the Rayleigh number increased. Moreover, his results indicated that the average heat transfer decreased with increasing the length of the heater embedded on the left wall. In a numerical study, Lin and Violi [16] studied the problem of natural convection heat transfer of $\mathrm{Al}_{2} \mathrm{O}_{3}$-water nanofluids in a vertical cavity with an added consideration of the slip mechanism in the nanofluids. The collective influence of non-uniform nanoparticle diameters, nanoparticles volume fractions, Prandtl number, and Grashof number on the flow and temperature distributions was analyzed exhaustively. In synthesis, it can be attested that natural convective heat transfer in enclosures filled with water can be enhanced by adding nanoparticles of copper, $\mathrm{Cu}$ [17-20], copper oxide $\mathrm{CuO}$ [21-23], silver $\mathrm{Ag}$ [24], alumina $\mathrm{Al}_{2} \mathrm{O}_{3}$ [25] and titanium $\mathrm{TiO}_{2}$ [26].

Natural convection heat transfer in closed enclosures having a heated block inside and filled with nanofluids has received considerable attention in recent years due to its practical applications, such as thermal insulation and/or building design. The problem of natural convection of a $\mathrm{Cu}$-water nanofluid placed inside a square cavity having adiabatic square bodies at its center has been investigated numerically by Mahmoudi and Sebdani using the finite volume method [27]. It was found that the rate of heat transfer augments by increasing the Rayleigh number when the volume fraction of the nanoparticles is kept constant. Also, the average Nusselt number invigorates with enlargements in the volume fraction of the nanoparticles. Arefmanesh et al. [28] conducted a sequence of numerical analyses of the buoyancy-driven heat transfer in the space between two differentially-heated square ducts filled with the $\mathrm{TiO}_{2}$-water nanofluid. A comprehensive parametric study involving the effects of the Rayleigh number, annulus aspect ratio, and the $\mathrm{TiO}_{2}$ volume fraction on the fluid flow and heat transfer patterns are conducted. Their results demonstrate that high Rayleigh numbers are eminently an effective parameter, causing the formation of the multiple vortices of the RayleighBénard convective type within the top portion of the annuli. Parvin et al. [29] studied numerically the problem of natural convection from a heated cylinder contained in a square enclosure filled with $\mathrm{Cu}$-water nanofluid. They found that using highly viscous nanofluid is an effective way to enhance the rate of heat transfer. Natural convection inside a two-dimensional square cavity filled with nanofluids with several pairs of heaters and coolers placed inside was investigated numerically by Garoosi et al. [30]. Individual effects of various design parameters, position, surface area, shape and orientation of heaters and coolers, on the heat transfer rate are shown.

In the present investigation, the problem of natural convection heat transfer and fluid flow in rectangular and square enclosures containing one or two heated cylindrical blocks and filled with four $\mathrm{Cu}$-water, Ag-water, $\mathrm{Al}_{2} \mathrm{O}_{3}$-water and $\mathrm{TiO}_{2}$-water nanofluids is examined numerically.

\section{Problem description and mathematical formulation}

Sketched in Figure 1 is a rectangular enclosure of width $2 H$ and height $H$ housing two heated circular blocks of small diameter, which are placed symmetrically. The primary fluids filling the rectangular enclosure are water-based nanofluids containing four different $\mathrm{Ag}, \mathrm{Cu}, \mathrm{Al}_{2} \mathrm{O}_{3}$ or $\mathrm{TiO}_{2}$ nanoparticles.

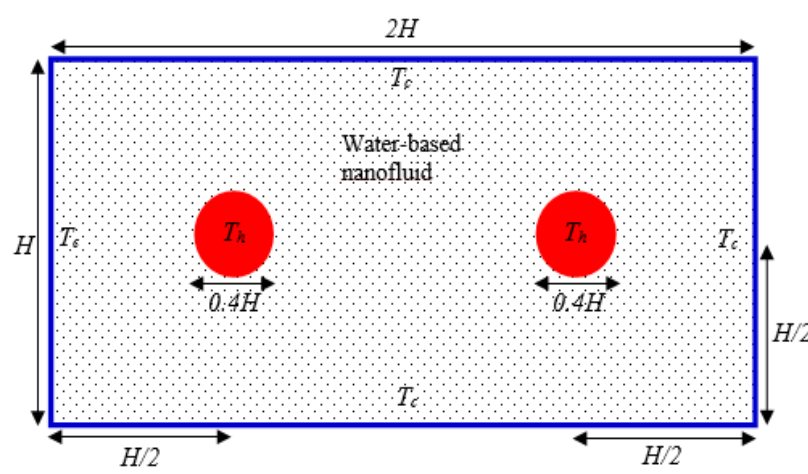

Figure 1 Schematic for the rectangular enclosure housing two heated circular blocks

The four nanoparticles: $\mathrm{Cu}, \mathrm{Al}_{2} \mathrm{O}_{3}, \mathrm{Ag}, \mathrm{TiO}_{2}$ have a uniform shape and size. The water-based nanofluids are assumed to be Newtonian and incompressible with laminar movement. Moreover, it is idealized that the fluid phase and nanoparticles are in a state of thermal equilibrium and both flow at the same velocity. The thermophysical properties of the nanofluids are considered to be constant, except for the density, which obeys the standard Boussinesq approximation. The thermophysical properties of the base fluid water and the nanoparticles $\mathrm{Cu}$, $\mathrm{Al}_{2} \mathrm{O}_{3}, \mathrm{Ag}, \mathrm{TiO}_{2}$ are reported in Table 1 . 
Table 1. Thermophysical properties of water, silver, copper, alumina and titanium oxide at $T=25^{\circ} \mathrm{C}$

\begin{tabular}{ccccc}
\hline & $\rho$ & $k$ & $c_{p}$ & $\beta$ \\
\hline Water & 997.1 & 0.613 & 4179 & $21 \times 10^{-5}$ \\
Silver $(\mathrm{Ag})$ & 10.5 & 429 & 235 & $1.89 \times 10^{-5}$ \\
Copper $(\mathrm{Cu})$ & 8933 & 401 & 385 & $1.67 \times 10^{-5}$ \\
Alumina $\left(\mathrm{Al}_{2} \mathrm{O}_{3}\right)$ & 3970 & 40 & 765 & $0.85 \times 10^{-5}$ \\
Titanium $\left(\mathrm{TiO}_{2}\right)$ & 4250 & 8.95 & 686 & $0.90 \times 10^{-5}$ \\
\hline
\end{tabular}

The coupled system of conservation equations describing the two-dimensional flow of the water-based nanofluids consists of: Continuity equation

$\frac{\partial u_{i}}{\partial x_{i}}=0 \quad(i=1,2)$

Momentum equation

$\frac{\partial u_{i}}{\partial t}+\frac{\partial u_{i} u_{j}}{\partial x_{j}}=-\frac{1}{\rho_{n f}} \frac{\partial P}{\partial x_{i}}+\frac{\mu_{n f}}{\rho_{n f}} \frac{\partial^{2} u_{i}}{\partial x_{j} \partial x_{j}}+\frac{\left(\rho \beta_{n f}\right.}{\rho_{n f}} g\left(T-T_{C}\right) \delta_{i 2} \quad(i, j=1,2)$

where the symbol $\delta_{i, j}$ stands for the Kronecker delta.

Energy equation

$\frac{\partial T}{\partial t}+\frac{\partial\left(u_{i} T\right)}{\partial x_{j}}=\alpha_{n f} \frac{\partial^{2} T}{\partial x_{j} x_{j}} \quad(i, j=1,2)$

In Eqs. (2) and (3), the dependent variables are: $u_{i}=(u, v)$ the velocity components, $p$ is the kinematic pressure, and $T$ is the temperature.

The customary dimensionless variables

$X=\frac{x}{H}, Y=\frac{y}{H}, U=\frac{u}{\sqrt{g \beta \Delta T H}}, V=\frac{v}{\sqrt{g \beta \Delta T H}}, P=\frac{p}{\rho g \beta_{f} \Delta T H}$, $\theta=\frac{T-T_{c}}{T_{h}-T_{c}}$.

are adopted in order to express Eqs. (1)-(3) in dimensionless form. That is, Continuity equation

$\frac{\partial U_{i}}{\partial X_{i}}=0 \quad(i=1,2)$

Momentum equation

$\frac{\partial U_{i}}{\partial \tau}+\frac{\partial\left(U_{i} U_{j}\right)}{\partial X_{j}}=-\frac{\partial P}{\partial X_{i}}+\frac{\mu_{n f}}{\rho_{n f} \alpha_{f}} \frac{\partial^{2} U_{i}}{\partial X_{j} \partial X_{j}}+\frac{(\rho \beta)_{n f}}{\rho_{n f} \beta_{f}} \operatorname{Ra} \operatorname{Pr} \theta \delta_{i 2} \quad(i, j=1,2)$

where $R a=\frac{g \beta H^{3} \Delta T}{v \alpha}$ is the height-based Rayleigh number and $\operatorname{Pr}=\frac{v}{\alpha}$ is the Prandtl number.
Energy equation

$\frac{\partial \theta}{\partial \tau}+\frac{\partial U_{i} \theta}{\partial X_{j}}=\frac{\alpha_{n f}}{\alpha_{f}} \frac{\partial^{2} \theta}{\partial X_{j} \partial X_{j}} \quad(i, j=1,2)$

The applicable dimensionless velocity and temperature boundary conditions take the following form:

$U=V=0$ on all walls of the rectangular enclosure.

$\theta=1$ at the surfaces of the two circular blocks.

$\theta=0$ on all walls of the rectangular enclosure.

Once the dimensionless velocity fields $U(X, Y), V(X, Y)$ and the dimensionless temperature field $\theta(X, Y)$ are numerically obtained, the local convection coefficient $h_{n f}$ can be determined. From here, the local Nusselt number $N u$ defined by

$$
N u=\frac{h_{n f} H}{k_{n f}}
$$

is computed with

$$
N u=-\frac{k_{n f}}{k_{f}}\left(\frac{\partial \theta}{\partial n}\right)_{\text {wall }}
$$

Subsequently, the averaged Nusselt number $\overline{N u}$, is calculated with the integral

$$
\overline{N u}=\frac{1}{S} \iint_{S} N u d S
$$

\section{Effective thermophysical properties of nanofluids}

The effective thermophysical properties of the nanofluids can be evaluated using the recommended formulas in the literature. Recall that $\varphi$ identifies the volume fraction of the nanoparticles.

1) The effective density $\rho_{n f}$ is given by the weighted relation:

$$
\rho_{n f}=(1-\varphi) \rho_{f}+\varphi \rho_{p}
$$

2) The effective dynamic viscosity $\mu_{n f}$ is expressed by Brinkman's formula [31]:

$\mu_{n f}=\frac{\mu_{f}}{(1-\varphi)^{2.5}}$

3) The effective thermal expansion coefficient $(\rho \beta)_{n f}$ is given by the weighted relation:

$(\rho \beta)_{n f}=(1-\varphi)(\rho \beta)_{f}+\varphi(\rho \beta)_{p}$

4) The effective thermal diffusivity $\alpha_{n f}$ is evaluated from the definition: 


$$
\alpha_{n f}=\frac{k_{n f}}{\left(\rho c_{p}\right)_{n f}}
$$

5) The effective thermal conductivity is determined according to Maxwell model [32]:

$$
\frac{k_{n f}}{k_{f}}=\frac{\left(k_{p}+2 k_{f}\right)-2 \varphi\left(k_{f}-k_{p}\right)}{\left(k_{p}+2 k_{f}\right)+\varphi\left(k_{f}-k_{p}\right)}
$$

6) The effective specific heat capacitance is computed with the weighted relation given by Xuan and Roetzel [33]:

$$
\left(\rho c_{p}\right)_{n f}=(1-\varphi)\left(\rho c_{p}\right)_{f}+\varphi\left(\rho c_{p}\right)_{p}
$$

In the preceding eqs. (9) - (14), the subscripts $f$ and $p$ denote base fluid and nanoparticles, respectively.

\section{Computational methodology}

The coupled system of dimensionless Navier-Stokes and energy equations (4), (5) and (6) was numerically solved using the finite-volume method attributed to Patankar [34]. The temporal discretization of the time derivative is performed using an Euler backward second-order implicit scheme. The non-linear terms are evaluated explicitly, while the viscous terms are treated implicitly. A projection method is employed to couple the momentum and continuity equations (Achdou and Guermond [35]). An intermediate velocity is first computed and later updated to comply with mass continuity requirements. In the intermediate velocity field, the old pressure is used. A Poisson equation, with the divergence of the intermediate velocity field as the source term, is then solved to obtain the pressure correction and afterward the real velocity field. The advective terms are discretized using a QUICK third-order scheme (Leonard $[36,37]$ in the momentum equation and a second order central differencing one in the energy equation. The discretized momentum and energy equations are solved using the red and black successive over relaxation method RBSOR (Ben Cheikh et al. [38]) with the choice of optimum relaxation factors. In addition, the Poisson pressure correction equation is solved using an accelerated multi-grid method (Ben Cheikh et al. [38])

\subsection{Code validation}

The validity of the numerical code is tested in two stages. In the first stage, a natural convection heat transfer in a square enclosure with a circular heated block located in the center and filled with air $(\operatorname{Pr}=0.71)$ is studied. The domain and the boundary conditions are similar that those shown in Figure 2. The numerical simulations are performed for Rayleigh numbers varying from $R a=10^{4}$ to $10^{6}$ and different grid sizes owing $40^{2}, 80^{2}, 160^{2}$ and $320^{2}$ nodes.

A two-dimensional solution for unsteady natural convection in a square cavity was obtained by Kim et al. [39], using the Immersed Boundary Method (IBM) to model an inner circular cylinder based on the finite volume method for different Rayleigh numbers varying over the range of $10^{3}-10^{6}$.The validity of the numerical code is tested in two stages. In the first stage, Table 2 lists comparisons between the average Nusselt numbers $\overline{N u}$ through the wall of the heated cylinder obtained by the present simulation with the results of Kim et al. [39]. As the numbers in the table show, very good agreements exist between the results of the current simulation and those of Kim et al. [39]. In the second stage, a problem for natural convection in a differentially heated square enclosure filled with two $\mathrm{Cu}$-water or $\mathrm{Al}_{2} \mathrm{O}_{3}$-water nanofluids is solved. The simulations are performed for a range of solid volume fractions $0 \leq \varphi \leq 0.06$ along with $R a=10^{4}$ and $10^{5}$. Tables 3 and 4 contain comparisons between the average Nusselt number $\overline{N u}$ obtained by the present simulation with the results of Roslan et al. [40], Khanafer et al. [10] and Ho et al. [12]. As it is observed from the sequence of numbers, very good agreements are in evidence between the results.

(a) $\mathrm{Ra}=10^{3}$
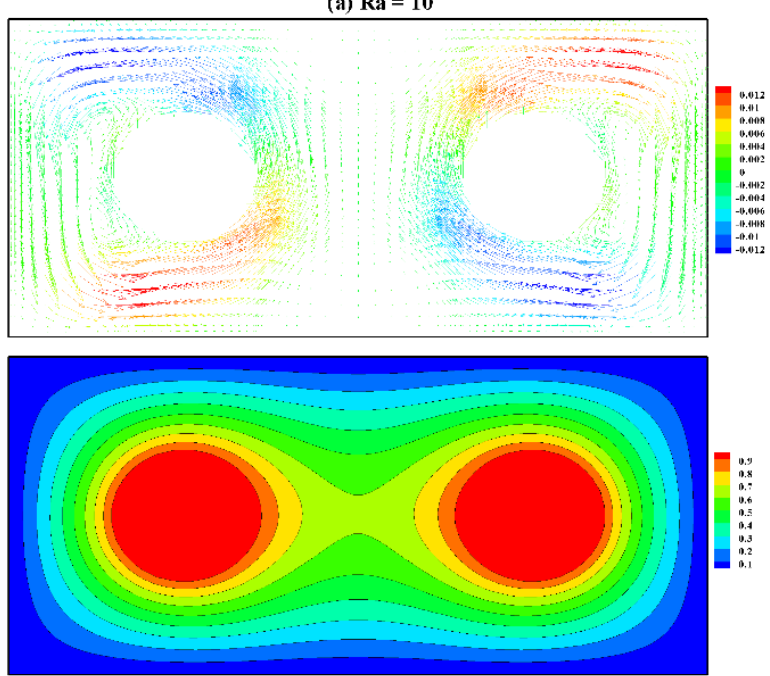

(b) $\mathrm{Ra}=10^{5}$
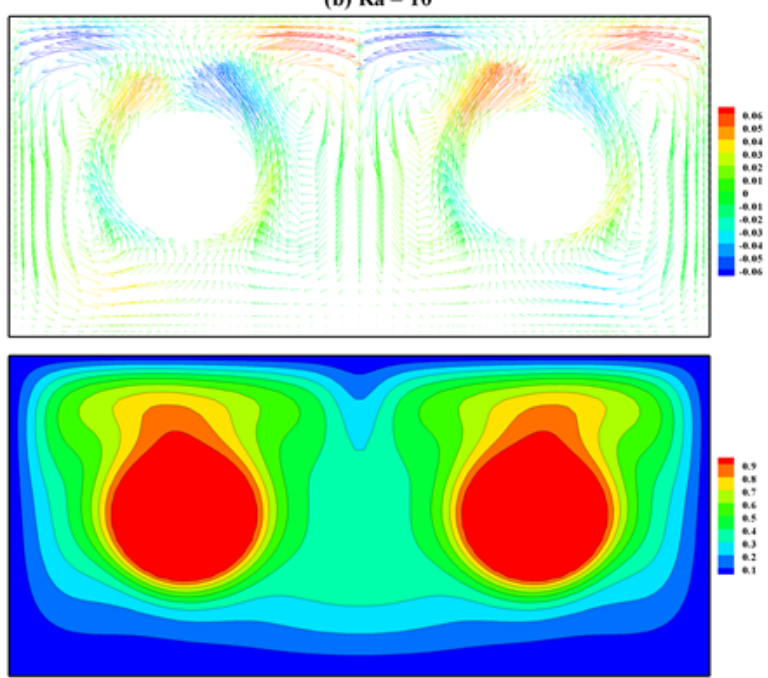

Figure 2 Velocity vectors (top) and isotherms (bottom) for a $\mathrm{Cu}$ water nanofluid with fixed $\varphi=0.04$ in a horizontal rectangular enclosure at $\gamma=0^{\circ}$. Part a) $R a=10^{3}$ and Part b) $R a=10^{5}$ 
Table 2. Comparison of the computed average Nusselt numbers $\overline{\mathrm{Nu}}$ for a regular fluid with those reported by Kim et al. [39].

\begin{tabular}{ccccc}
\hline \multirow{2}{*}{ Grid sizes } & $R a$ & \multicolumn{2}{c}{ Average Nusselt } & \multirow{2}{*}{ Relative } \\
\cline { 3 - 4 } & & $\begin{array}{c}\text { Present } \\
\text { study }\end{array}$ & $\begin{array}{c}\text { Ref. } \\
\text { d }\end{array}$ & difference \\
(\%)
\end{tabular}

Table 3. Comparison of the computed average Nusselt numbers $\overline{\mathrm{Nu}}$ for a Cu-water nanofluid with those reported by Roslan et al. [40] and Khanafer et al. [10].

\begin{tabular}{|c|c|c|c|c|c|c|}
\hline \multirow[b]{2}{*}{$R a$} & \multirow[b]{2}{*}{$\varphi$} & \multicolumn{3}{|c|}{$\begin{array}{l}\text { Average Nusselt number } \\
\qquad N u\end{array}$} & \multicolumn{2}{|c|}{$\begin{array}{c}\text { Relative } \\
\text { difference (\%) }\end{array}$} \\
\hline & & $\begin{array}{l}\text { Present } \\
\text { study }\end{array}$ & $\begin{array}{l}\text { Ref. } \\
{[40]}\end{array}$ & $\begin{array}{l}\text { Ref. } \\
{[10]}\end{array}$ & 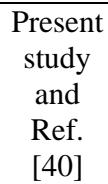 & $\begin{array}{c}\text { Present } \\
\text { study } \\
\text { and } \\
\text { Ref. } \\
\text { [10] }\end{array}$ \\
\hline \multirow{6}{*}{$10^{4}$} & 0.00 & 2.274 & 2.272 & 2.299 & 0.088 & 1.087 \\
\hline & 0.01 & 2.296 & 2.304 & 2.335 & 0.347 & 1.670 \\
\hline & 0.02 & 2.318 & 2.326 & 2.375 & 0.344 & 2.400 \\
\hline & 0.03 & 2.339 & 2.357 & 2.417 & 0.764 & 3.227 \\
\hline & 0.04 & 2.360 & 2.388 & 2.459 & 1.172 & 4.026 \\
\hline & 0.05 & 2.380 & 2.409 & 2.503 & 1.204 & 4.914 \\
\hline \multirow{6}{*}{$10^{5}$} & 0.00 & 4.720 & 4.716 & 4.720 & 0.085 & 0.000 \\
\hline & 0.01 & 4.775 & 4.771 & 4.793 & 0.084 & 0.375 \\
\hline & 0.02 & 4.829 & 4.825 & 4.875 & 0.083 & 0.943 \\
\hline & 0.03 & 4.882 & 4.877 & 4.960 & 0.102 & 1.572 \\
\hline & 0.04 & 4.933 & 4.949 & 5.048 & 0.323 & 2.278 \\
\hline & 0.05 & 4.984 & 5.079 & 5.137 & 1.870 & 2.978 \\
\hline
\end{tabular}

Table 4. Comparison of the computed average Nusselt numbers $\overline{N u}$ for a $\mathrm{Al}_{2} \mathrm{O}_{3}$-water nanofluid with those reported by Roslan et al. [40] and Ho et al. [12].

\begin{tabular}{|c|c|c|c|c|c|c|}
\hline \multirow[b]{2}{*}{$R a$} & \multirow[b]{2}{*}{$\varphi$} & \multicolumn{3}{|c|}{$\begin{array}{l}\text { Average Nusselt number } \\
\qquad \mathrm{Nu}\end{array}$} & \multicolumn{2}{|c|}{$\begin{array}{c}\text { Relative } \\
\text { difference (\%) }\end{array}$} \\
\hline & & $\begin{array}{l}\text { Present } \\
\text { study }\end{array}$ & $\begin{array}{l}\text { Ref. } \\
{[40]}\end{array}$ & $\begin{array}{l}\text { Ref. } \\
{[12]}\end{array}$ & $\begin{array}{c}\text { Present } \\
\text { study } \\
\text { and } \\
\text { Ref. } \\
\text { [40] }\end{array}$ & 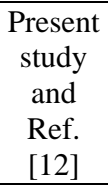 \\
\hline \multirow{6}{*}{$10^{4}$} & 0 & 2.274 & 2.272 & 2.297 & 0.088 & 1.001 \\
\hline & 0.01 & 2.289 & 2.299 & 2.335 & 0.434 & 1.970 \\
\hline & 0.02 & 2.303 & 2.311 & 2.372 & 0.346 & 2.908 \\
\hline & 0.03 & 2.316 & 2.337 & 2.410 & 0.898 & 3.900 \\
\hline & 0.04 & 2.329 & 2.361 & 2.448 & 1.355 & 4.861 \\
\hline & 0.05 & 2.341 & 2.399 & 2.487 & 2.418 & 5.870 \\
\hline \multirow{6}{*}{$10^{5}$} & 0 & 4.720 & 4.716 & 4.552 & 0.085 & 3.691 \\
\hline & 0.01 & 4.761 & 4.757 & 4.626 & 0.084 & 2.918 \\
\hline & 0.02 & 4.801 & 4.796 & 4.701 & 0.104 & 2.127 \\
\hline & 0.03 & 4.839 & 4.834 & 4.776 & 0.103 & 1.319 \\
\hline & 0.04 & 4.876 & 4.871 & 4.851 & 0.103 & 0.515 \\
\hline & 0.05 & 4.911 & 4.936 & 4.927 & 0.506 & 0.325 \\
\hline
\end{tabular}

\subsection{Grid independence}

In order to find a reasonable compromise between the calculation time and the accuracy of the results, a grid independence study is conducted for the natural convection heat transfer. Four grids of different sizes were tested to ensure the independence of the results from the mesh. The difference between the solutions obtained on the grid with $160^{2}$ nodes and those obtained on the grid with $80^{2}$ nodes is less than $1.4 \%$. This is the reason why the grid with $80^{2}$ nodes was chosen for all simulations in this study.

\section{Results and discussions}

The rectangular enclosures are governed by the following controlling parameters: the Rayleigh number $10^{3} \leq R a \leq 10^{6}$, the solid volume fraction $0 \leq \varphi \leq 0.06$ and the inclination angle $0^{\circ} \leq \gamma \leq 180^{\circ}$. The enclosures are filled with the four $\mathrm{Cu}$-water, Ag-water, $\mathrm{Al}_{2} \mathrm{O}_{3}$-water and $\mathrm{TiO}_{2}$-water nanofluids. The Prandtl number of the dominant water is reasonably set at $\mathrm{Pr}=6.2$.

The velocity vectors and isotherms inside the enclosure filled with a Cu-water nanofluid at $\varphi=0.04, R a=10^{3}$ and $10^{5}$ are shown in Figure 2. At a low $R a=10^{3}$, the flow patterns are characterized by two counter-rotating roll cells that occupy the bulk of the enclosure. The uniformly distributed isotherms at low Rayleigh number $\left(R a=10^{3}\right)$ show that the main heat transfer mechanism is through heat conduction. When the Rayleigh number elevates from $10^{3}$ to $10^{5}$, the flow intensity increases and each cell break into two symmetrical eddies. At this Rayleigh number, the isotherms move upward giving rise to a stronger thermal gradient in the upper part of the enclosure which indicates that the heat transfer mechanism is changing from conduction to convection.

Figure 3 exhibits the distribution of local Nusselt number along the walls of the rectangular enclosure filled with a $\mathrm{Cu}$-water nanofluid at $\varphi=0.04$ along with two $R a=10^{3}$ and $10^{5}$. The isotherms presented in Figure 2a show a symmetric shape with respect to the vertical center line at $X=1$ and the horizontal center line at $Y=0.5$, because the dominant effect is heat conduction. As a result, the distribution of the local Nusselt number $N u$ along the top and bottom walls of the enclosure reflects a symmetric shape with respect to $X=1$ and the distribution of the local Nusselt numbers along the vertical walls (left and right) of the enclosure exhibits the symmetric shape with respect to $Y=0.5$ (see Figure 3a). The local Nusselt number attains a maximum value at $X=0.5, X=1.5$ and $Y=0.5$, which are the closest point on the enclosure walls to the two heated blocks. As can be seen from Figure $3 b$ when we increase Rayleigh number from $10^{3}$ to $10^{5}$, the values of the local Nusselt along the bottom wall of the enclosure become little compared to that along the top wall, due to the stronger thermal gradient in the upper part of the enclosure as it is shown in Figure2b. For $R a$ $=10^{5}$, the symmetry in the isotherms with respect to the horizontal center line at $Y=0.5$ is broken as shown in Figure 2b and as a result the symmetry of the local Nusselt number along the vertical walls is also broken at $R a=10^{5}$. Otherwise, the maximum value of Nusselt number $N u_{\max }$ along the left and right walls are relocated around $Y=0.8$. 
(a) $\mathrm{Ra}=10^{3}$
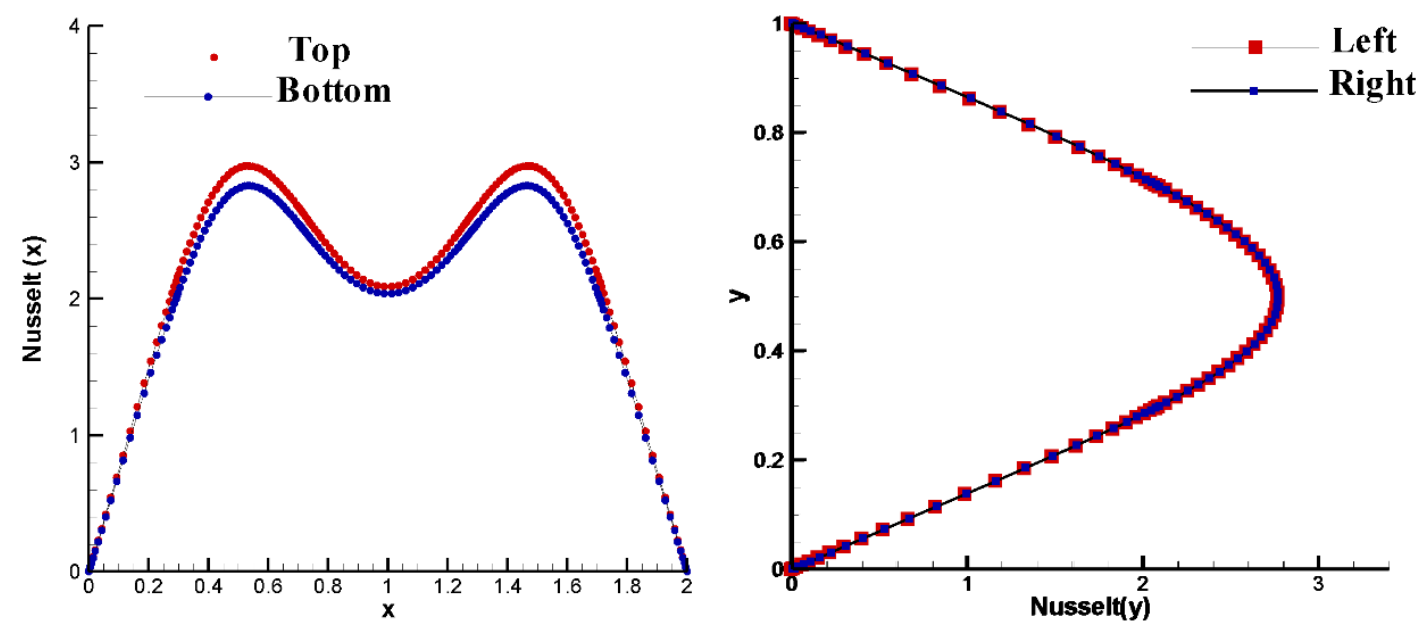

(b) $\mathrm{Ra}=10^{5}$
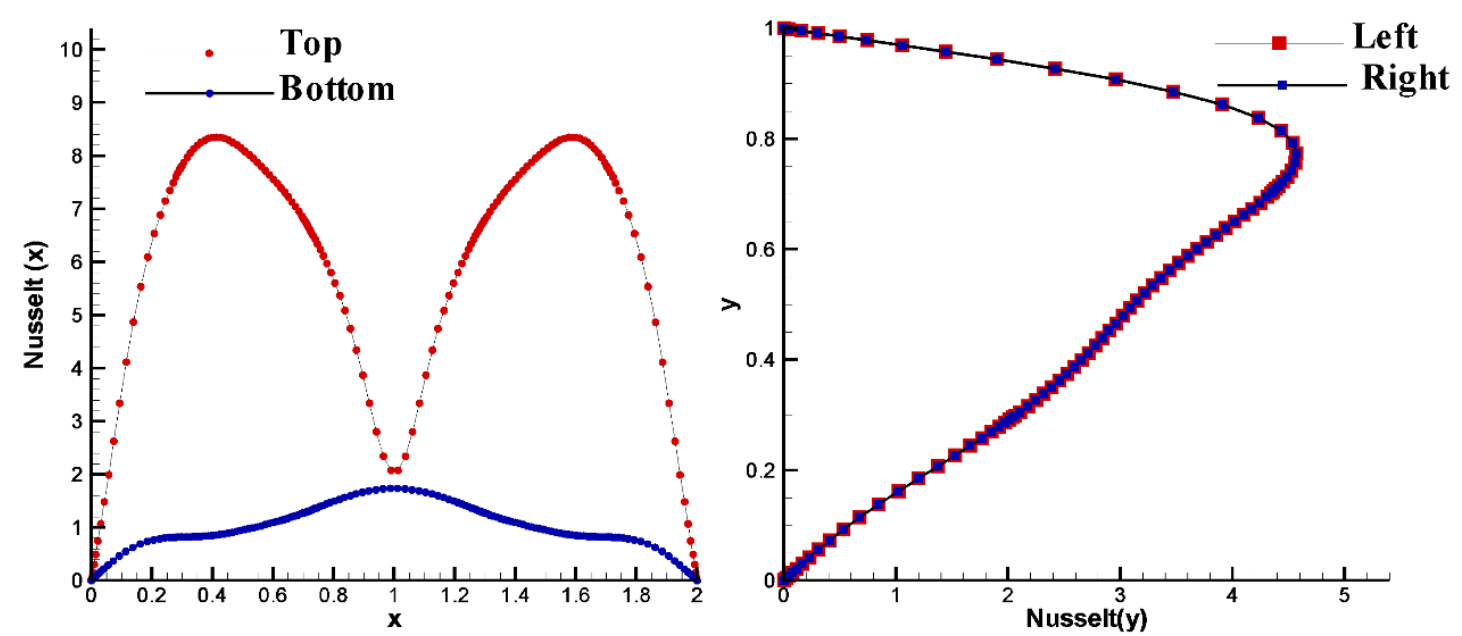

Figure 3. Local Nusselt number $\mathrm{Nu}$ along the two walls of the horizontal rectangular enclosure $\gamma=0^{\circ}$ filled with a $\mathrm{Cu}$-water nanofluid with fixed $\varphi=0.04$. The parameters are: Part a) $R a=10^{3}$ and Part b) $R a=10^{5}$

The bearing that the inclination angle has on the velocity vectors and isotherms are illustrated in Figure 4 for $\gamma=45^{\circ}$ and Figure 5 for $\gamma=90^{\circ}$ using a Cu-water nanofluid embodying $\varphi=0.04$ along with different Rayleigh number values. It is clearly seen from these two figures that the isotherms have the same shape as those for low Rayleigh numbers. The isotherms behavior insinuate that the temperature gradients in the upper corner of the enclosure increases with increasing the inclination angle and the Rayleigh number. By comparison to the velocity vectors distribution presented in Figure 2, the flow patterns are now characterised by many roll cells as evidenced in the tandem of Figures 4 and 5 .

Figure 6 was prepared to display the variation of the average Nusselt number $\overline{N u}$ along the wall of the rectangular enclosures for inclination angles within $0^{\circ} \leq \gamma \leq 180^{\circ}$. In this figure, the value of the average Nusselt number $\overline{\mathrm{Nu}}$ reaches a maximum around $\gamma=90^{\circ}$ and contrarily reaches a minimum for $\gamma=0^{\circ}$ and $\gamma=180^{\circ}$ for low Rayleigh number. When the Rayleigh number increases to $R a=5 \times 10^{4}$ and $10^{5}$, the value of the average Nusselt number is attains a maximum $\overline{N u}$ max at $\gamma=90^{\circ}$ (vertical rectangular enclosure) and attains a minimum $\overline{N u} \min$ at $\gamma=45^{\circ}$ and $\gamma=135^{\circ}$ (inclined rectangular enclosure).

For purposes of quantifying the heat transfer enhancement due to the addition of the four different nanoparticles $\mathrm{Cu}, \mathrm{Ag}, \mathrm{Al}_{2} \mathrm{O}_{3}$ and $\mathrm{TiO}_{2}$ to the common fluid water, the prevalent working formula is

$$
E=\frac{\overline{N u}(\text { nanofluid })-\overline{N u}(\text { water })}{\overline{N u}(\text { water })} \times 100 \%
$$



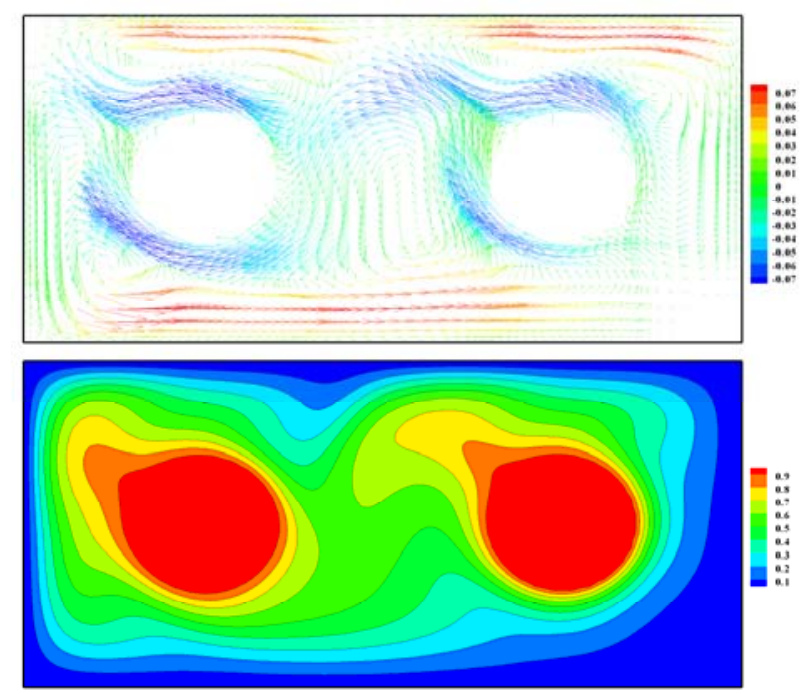

(a)
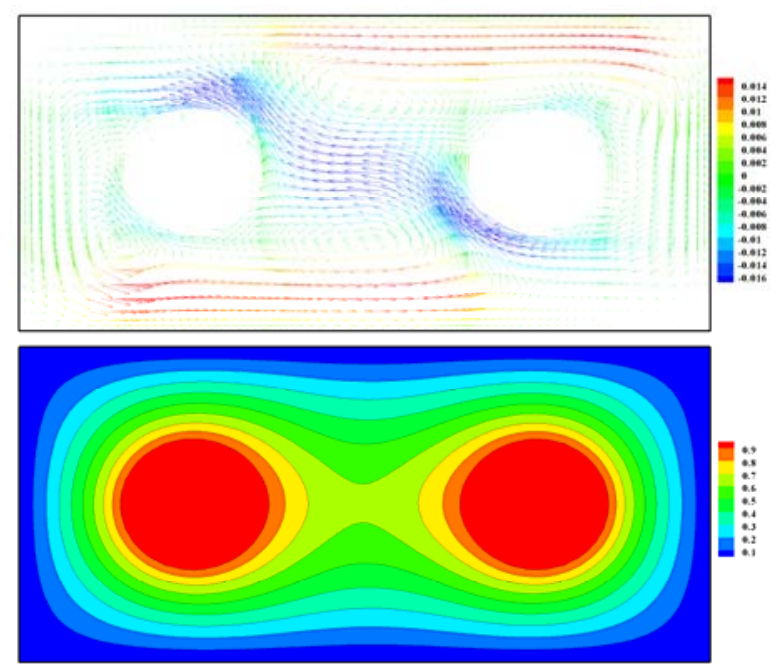

(b)

Figure 4. Velocity vectors (top) and isotherms (bottom) for a rectangular enclosure at an inclination angle $\gamma=45^{\circ}$ filled with a $\mathrm{Cu}$ water nanofluid with fixed $\varphi=0.04$. The parameters are: Part (a) $\boldsymbol{R} a$ $=10^{3}$ and Part (b) $R a=10^{5}$.
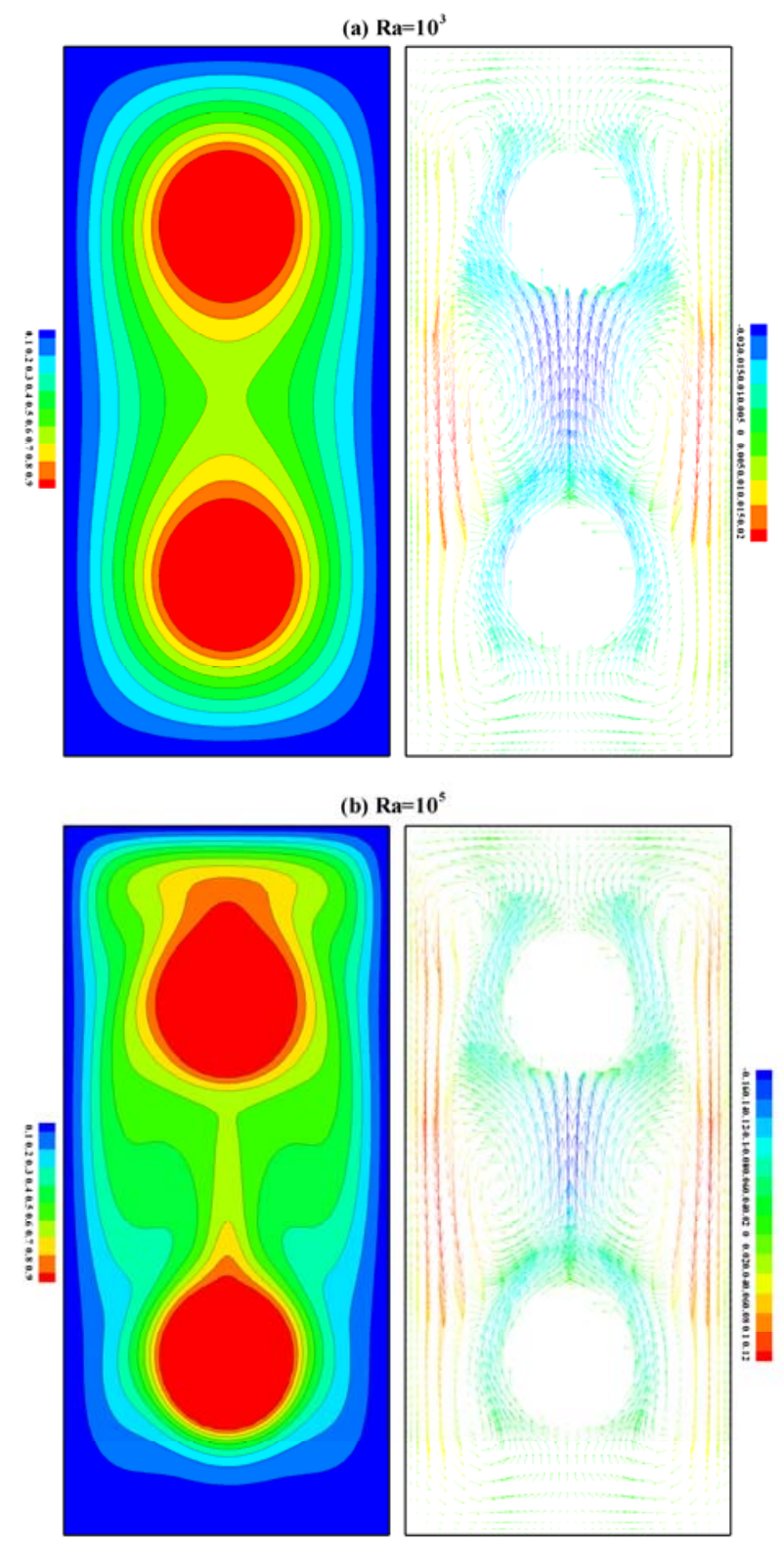

Figure 5. Velocity vectors (top) and isotherms (bottom) for a vertical rectangular enclosure at an inclination angle $\gamma=90^{\circ}$ filled with a $\mathrm{Cu}$ water nanofluid with fixed $\varphi=0.04$. The parameters are: Part (a) $R a$ $=10^{3}$ and Part (b) $R a=10^{5}$. 

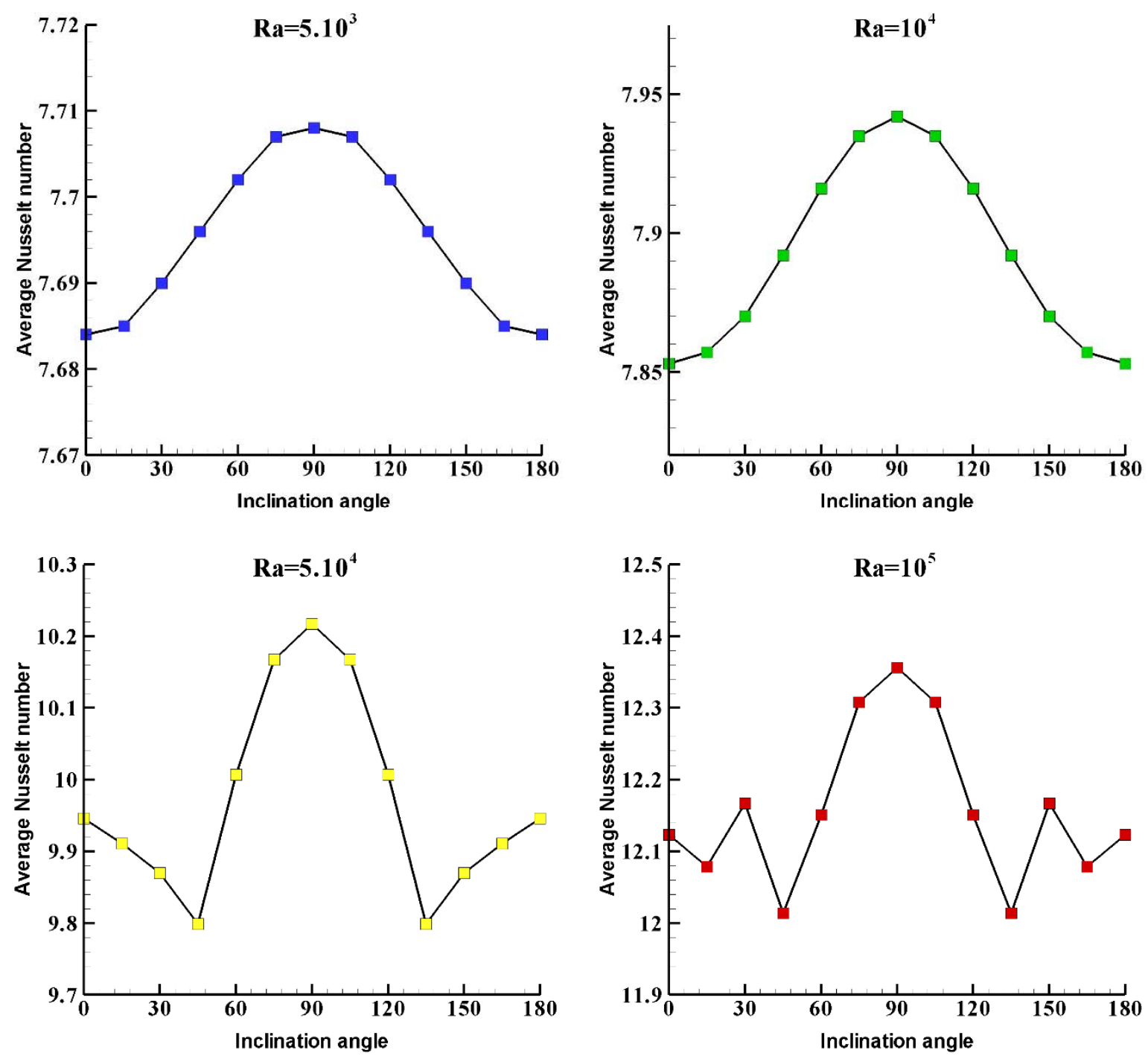

Figure 6. Variation of the average Nusselt number $\overline{N u}$ with the inclination angle $0^{\circ} \leq \gamma \leq 180^{\circ}$ for a Cu-water nanofluid with fixed $\varphi=0.04$. The parameters are: $R a=5 \times 10^{3}, 10^{4}, 5 \times 10^{4}$ and $10^{5}$.

\section{Conclusions}

Natural convection heat transfer of nanofluids filling a rectangular enclosure of aspect ratio two-to-one and housing two heated blocks placed symmetrically was investigated numerically. Simultaneous effects of the type of nanoparticles $\mathrm{Cu}, \mathrm{Ag}, \mathrm{Al}_{2} \mathrm{O}_{3}$ and $\mathrm{TiO}_{2}$, the volume fraction of nanoparticles, and the inclination angle on the fluid flow, temperature field, local and average Nusselt number and the heat transfer rate were examined for selected height-based Rayleigh numbers.

\section{References}

[1] A. Bejan, Convection Heat Transfer, 4th Edition, Wiley, Hoboken, NJ, 2013.

[2] J.A. Eastman, S.U.S. Choi, S. Li, W. Yu, L.J. Thompson, Anomalously increased effective thermal conductivities of ethylene glycolbased nanofluids containing copper nanoparticles, Appl. Phys. Lett. 78 (2001) 718-720.

[3] H. Xie, J. Wang, T.G. Xie, Y. Liu, F. Ai, Thermal conductivity enhancement of suspensions containing nanosized alumina particles, J. Appl. Phys. 91 (2002) 4568-4572.

[4] L. Godson, B. Raja, D.M. Lal, S. Wongwises, Enhancement of heat transfer using nanofluids-An overview, Renewable Sustainable Energy Reviews 14 (2010) 629-641.

[5] R.S. Vajjha, D.K. Das, Experimental determination of thermal conductivity of three nanofluids and development of new correlations, Int. J. Heat Mass Transfer 52 (2009) 4675-4682. 
[6] M. Corcione, Heat transfer features of buoyancydriven nanofluids inside rectangular enclosures differentially heated at the sidewalls, Int. J. Therm. Sci. 49 (2010) 1536-1546.

[7] M. Corcione, Empirical correlating equations for predicting the effective thermal conductivity and dynamic viscosity of nanofluids, Energy Conversion Management 52 (2011) 789-793.

[8] A.T. Utomo, H. Poth, P.T. Robbins, A.W. Pacek, Experimental and theoretical studies of thermal conductivity, viscosity and heat transfer coefficient of titania and alumina nanofluids, Int. J. Heat Mass Transfer 55 (2012) 7772-7781.

[9] Z. Haddad, H.F. Oztop, E. Abu-Nada, A. Mataoui, A review on natural convective heat transfer of nanofluids, Renewable Sustainable Energy Reviews 16 (2012) 5363-5378.

[10] K. Khanafer, K. Vafai, M. Lightstone, Buoyancydriven heat transfer enhancement in two-dimensional enclosure utilizing nanofluid, Int. J. Heat Mass Transfer 46 (2003) 3639-3653.

[11] R.Y. Jou, S.C. Tzeng, Numerical research of nature convective heat transfer enhancement filled with nanofluids in rectangular enclosures, Int. Comm. Heat Mass Transfer 33 (2006) 727-736.

[12] C.J. Ho, M.W. Chen, Z.W. Li, Numerical simulation of natural convection of nanofluid in a square enclosure: effects due to uncertainties of viscosity and thermal conductivity, Int. J. Heat Mass Transfer 51 (2008) 4506-4516.

[13] C.J. Ho, W.K. Liu, Y.S. Chang, C.C. Lin, Natural convection heat transfer of alumina-water nanofluid in vertical square enclosures: An experimental study, Int. J. Therm. Sci. 49 (2010) 1345-1353.

[14] E. Abu-Nada, H. Oztop, Effect of inclination angle on natural convection in enclosures filled with $\mathrm{Cu}$-water nanofluids, Int. J. Heat Fluid Flow 30 (2009) 669-678.

[15] E.B. Ogut, Natural convection of water-based nanofluids in an inclined enclosure with a heat source, Int. J. Therm. Sci. 48 (2009) 2063-2073.

[16] K.C. Lin, Angela Violi, Natural convection heat transfer of nanofluids in a vertical cavity: Effects of non-uniform particle diameter and temperature on thermal conductivity. Int. J. Heat Fluid Flow 31 (2010) 236-245.

[17] R.Y. Jou, S.C. Tzeng, Numerical research of nature convective heat transfer enhancement filled with nanofluids in rectangular enclosures, Int. Comm. Heat Mass Transfer 33 (2006) 727-736.

[18] M.K. Das, P.S. Ohal, Natural convection heat transfer augmentation in a partially heated and partially cooled square cavity utilizing nanofluids, Int. J. Numer. Meth. Heat Fluid Flow 19 (2009) 411-431.

[19] G.A. Sheikhzadeh, A. Arefmanesh, M.H. Kheirkhah, R. Abdollahi, Natural convection of $\mathrm{Cu}$-water nanofluid in a cavity with partially active side walls, European J. Mechanics B/Fluids 30 (2011) 166-176.

[20] A.K. Santra, S. Sen, N. Chakraborty, Study of heat transfer augmentation in a differentially heated square cavity using copper-water nanofluid, Int. J. Therm. Sci. 47 (2008) 1113-1122.

[21] B. Ghasemi, S.M. Aminossadati, Natural convection heat transfer in an inclined enclosure filled with a water-CuO nanofluid, Numer. Heat Transfer, Part A 55 (2009) 807-823.

[22] S.M. Aminossadati, B. Ghasemi, Natural convection of water-CuO nanofluids in a cavity with two pairs of heat source-sink, Int. Comm. Heat Mass Transfer 38 (2011) 672-678.

[23] H.F. Oztop, M. Mobedi, E. Abu-Nada, I. Pop, A heatline analysis of natural convection in a square inclined enclosure filled with a $\mathrm{CuO}$ nanofluid under non-uniform wall heating condition, Int. J. Heat Mass Transfer 55 (2012) 5076-5086.

[24] M. Mahmoodi, Numerical simulation of free convection of nanofluids in a square cavity with an inside heater, Int. J. Therm. Sci. 50 (2011) 2161-2175.

[25] H.F. Oztop, E. Abu-Nada, Numerical study of natural convection in partially heated rectangular enclosures filled with nanofluids, Int. J. Heat Fluid Flow 29 (2008) 1326-1336.

[26] G.A. Sheikhzadeh, A. Arefmanesh, M. Mahmoodi, Numerical study of natural convection in a differentially-heated rectangular cavity filled with TiO2-water nanofluid, J. Nano Research 13 (2011) 75-80.

[27] M. Mahmoudi, S.M. Sebdani, Natural convection in a square cavity containing a nanofluid and an adiabatic square block at the center, Superlattices and Microstructures 52 (2012) 261-275.

[28] A. Arefmanesh, M. Amini, M. Mahmoudi, M.Najafi, Buoyancy-driven heat transfer analysis in two-square duct annuli filled with a nanofluid, European $\mathrm{J}$. Mechanics B/Fluids 33 (2012) 95-104.

[29] S. Parvin, M.A. Alim, N.F. Hossain, Prandtl number effect on cooling performance of heated cylinder in an enclosure filled with nanofluid, Int. Comm. Heat Mass Transfer 39 (2012) 1220-1225.

[30] F. Garoosi, G. Bagheri, F. Talebi, Numerical simulation of natural convection of nanofluids in a square cavity with several pairs of heaters and coolers (HACs) inside, Int. J. Heat Mass Transfer 67 (2013) 362-376. 
[31] H.C. Brinkman, The viscosity of concentrated suspensions and solution, J. Chem. Phys. 20 (1952) $571-581$.

[32] J. Maxwell, A Treatise on Electricity and Magnetism, second ed., pp. 435-441, Oxford University Press, Cambridge, UK, 1904.

[33] Y. Xuan, W. Roetzel, Conceptions for heat transfer correlation of nanofluids. Int. J. Heat Mass Transfer 43 (2000) 3701-3707.

[34] S.V. Patankar, Numerical Heat Transfer and Fluid Flow, pp. 113-137, McGraw-Hill, New York, 1980.

[35] Y. Achdou, J.L. Guermond, Convergence analysis of a finite element projection Lagrange-Galerkin method for the incompressible Navier-Stokes equations, SIAM J. Numer. Analysis 37 (2000) 799-826.

[36] B.P. Leonard, A stable and accurate convective modelling procedure based on quadratic upstream interpolation, Comput. Meth. Appl. Mech. Engng. 19 (1979) 59-98.

[37] B.P. Leonard, Templates for the Solution of Linear Systems: Building Blocks for Iterative Methods, SIAM, Philadelphia, PA, USA, 1994.

[38] N. Ben-Cheikh, B. Ben Beya, T. Lili, Benchmark solution for time-dependent natural convection flows with an accelerated full-multigrid method, Numer. Heat Trans. (B) 52 (2007) 131-151.

[39] B.S. Kim, D.S. Lee, M.Y. Ha, H.S. Yoon, A numerical study of natural convection in a square enclosure with a circular cylinder at different vertical locations, Int. J. Heat Mass Transfer 51 (2008) 1888-1906.

[40] R. Roslan, H. Saleh, I. Hashim, Effect of rotating cylinder on heat transfer in a square enclosure filled with nanofluids, Int. J. Heat Mass Transfer 55 (2012) 7247-7256.

\section{Nomenclature}

\begin{tabular}{|c|c|}
\hline$c_{p}$ & specific heat capacity, $J \cdot \mathrm{kg}^{-1} \cdot \mathrm{K}^{-1}$ \\
\hline$G$ & gravitational acceleration, $m-s^{-2}$ \\
\hline$k$ & thermal conductivity, $W \cdot m^{-1} \cdot K^{-1}$ \\
\hline$h$ & convection coefficient, $W \cdot m^{-2} \cdot K^{-1}$ \\
\hline $\bar{h}$ & average convection coefficient, $W \cdot m^{-2} \cdot K^{-1}$ \\
\hline$H$ & height of rectangular enclosure, $m$ \\
\hline$N u$ & local Nusselt number \\
\hline$\overline{N u}$ & average Nusselt number \\
\hline$P$ & dimensionless pressure \\
\hline$P$ & pressure, $\mathrm{Pa}$ \\
\hline $\operatorname{Pr}$ & Prandtl number \\
\hline$R a$ & height-based Rayleigh number \\
\hline$T$ & temperature, $\mathrm{K}$ \\
\hline$T$ & time, s \\
\hline$u, v$ & velocity components in the $x, y$ directions \\
\hline$U, V$ & dimensionless velocity components \\
\hline$x, y$ & Cartesian coordinates, $m$ \\
\hline$X, Y$ & dimensionless Cartesian coordinates \\
\hline$\alpha$ & thermal diffusivity, $\mathrm{m}^{2} \cdot \mathrm{s}^{-1}$ \\
\hline$\beta$ & thermal expansion coefficient, $\mathrm{K}^{-1}$ \\
\hline$\gamma$ & inclination angle \\
\hline$\varphi$ & solid volume fraction \\
\hline$\Delta T$ & temperature difference, $\mathrm{K}$ \\
\hline$\mu$ & dynamic viscosity, $\mathrm{kg} \cdot \mathrm{m}^{-1} \cdot \mathrm{s}^{-1}$ \\
\hline$v$ & kinematic viscosity, $\mathrm{m}^{2} \cdot \mathrm{s}^{-1}$ \\
\hline$\theta$ & dimensionless temperature \\
\hline & density, $\mathrm{kg} \cdot \mathrm{m}^{-3}$ \\
\hline
\end{tabular}

